\title{
Job Satisfaction and Associated Factors among Nurses Working In the Operation Theater at Government Hospitals of Eastern Ethiopia, 2017
}

\author{
Admasu Belay ${ }^{1}$, Abdela Abdo² ${ }^{2}$ Temamen Tesfaye ${ }^{3}$ and Dagmawit Birhanu ${ }^{4}$ \\ ${ }^{1}$ Jimma University Institute of Health School of Nursing and Midwifery, Ethiopia \\ ${ }^{2}$ Arsi Zonal Health Office, Ethiopia \\ ${ }^{3}$ Jimma University Institute of Health School of Nursing and Midwifery, Ethiopia \\ ${ }^{4}$ Jimma University Institute of Health School of Nursing and Midwifery, Ethiopia
}

Received: May 18, 2018; Accepted: June 01, 2018; Published: June 18, 2018

*Corresponding author: Admasu Belay Gizaw, Jimma University Institute of Health School of Nursing and Midwifery, P.O.BOX: 378, Ethiopia. Tel: 251-925270512, 251471111458/60; Fax: 0471-11-14-50; E-mail: admasu2004@gmail.com

\begin{abstract}
Background: Job satisfaction is an essential part of nurses 'lives, influencing patient safety, productivity, performance, quality of care, retention, commitment to the organization and the profession. The aim of this study is to assess the level of job satisfaction and associated factors among nurses working in the operating theatre.

Method: Institutional based cross-sectional study design was conducted and Simple random sampling method was used to obtain the study participants. Data was collected using a structured selfadministered questionnaire, entered in to EPI data version 3.1and analyzed using SPSS version20. Associations for statistical significance were assessed using the 'chi square' test of association. P-values less than 0.05 were considered as statistically significant.

Results: The overall level of job satisfaction among nurses who work in operation theater was $48 \%$ room from the total participant $8(8.16 \%)$ of the respondents were satisfied 39 (39.8\%) moderately satisfied whereas the rest $52 \%$ was dissatisfied. Type hospital was the only variable that is significantly associated with job satisfaction.

Conclusion: The overall level of job satisfaction among nurses work in operation theater room was low Accordingly, working at operating room, type hospital were significantly associated with satisfaction of nurses working in the operating room .
\end{abstract}

Key words: Operating room; Job satisfaction

\section{Introduction}

The term Job satisfaction is refers to attitude, feeling and beliefs that people have about their work. Positive and favorable attitude towards the job indicate job satisfaction. It is defined by how employees feel about their jobs and different aspects of their jobs. It is one of the important variables in work and organizational psychology, used to determine the quality of health-care systems. Negative and unfavorable attitudes towards the job indicate job dissatisfaction $[1,23]$.

It is the degree to which employees have positive effective orientation towards employment by an organization. Job satisfaction has been conceptualized both globally (general satisfaction with job) and dimensionally (satisfaction with specific dimension of job such as remuneration, promotion and relation with colleagues). Job satisfaction has been linked to health worker motivation, stress burnout, absenteeism, intention to leave, and turnover [2]. Many studies have shown that job satisfaction can be influenced by a wide variety of factors such as Salary, working environment, opportunities for personal and professional development, manageable workload, effective supervision, recognition, perceptible progress of patient care outcome, positive relationships with co-workers, autonomy, and contingent rewards [4-6].

Professional nurses play a vital role it the provision of health care globally in emergence department. The performance of heath care worker, including professional nurse, link closely to productivity and quality of care provision with health care organization. It was important to identify factors influencing the performance of professional nurse if the quality of health care delivery was too improved [17].Different study at different parts of the world point out the importance of job satisfaction to an organization, profession, professionals and care consumers [1822]. The shortage of nurses and job dissatisfaction is a worldwide phenomenon including Ethiopia. Identifying satisfaction level and associated factors among nurses working in the operating theatre enable interventional measures are taken to improve the retention rate; it will improve nurse's work performance leading to better quality care to patient [19]. Therefore, this study aimed to determine the level of job satisfaction and associated factors among nurses working in the operating theatre at government hospitals.

\section{Method and Materials \\ Study Area and Period}

The study was conducted in governmental hospitals Found in 
East Arsi Oromia Regional state. Oromia region is one of the nine regional states of Federal Democratic Republic of Ethiopia (FDRE) and East Arsi is one of the 20 zone of Oromia Regional State . Assella is the capital city of the zone and it's found at distance of $171 \mathrm{~km}$ from to the East of Addis Ababa, capital city of Ethiopia. There are 6 government hospital in the zone which includes; Assella teaching,Abomsa hospital, Arsi Robe hospitals, Bokoji hospitals, Bale hospital and Karsa hospitals from December 1 2016 to June 30, 2017.

\section{Study Design}

Institution based cross-sectional study design was conducted.

\section{Sample Size Determination}

All nurses working in the operating theatre and willing to participate in the study at each Hospital was included.

\section{Data Collection Tool and Procedure}

A structured self-administered questionnaire was used to collect data. The questionnaires comprised of three main parts; socio demography, job satisfaction and response. Job satisfaction partly consisted of 20items. For each factor, a respondent can choose from a six-point Likert scale which representing various degrees of satisfaction: 1-very dissatisfied, 2-dissatisfied 3-somewhat dissatisfied, 4-somewhat satisfied, 5-satisfied, and 6-very satisfied.

\section{Data quality assurance}

To ensure validity of the instrument, the questionnaire was submitted to the supervisor for comment regarding the relevance of each item, pre-testing of the questionnaire was done on twenty of the sample size outside of the study area, possible amendments were made. Training was given for the data collectors. During the data collection, supervision was done by principal investigator. Data cleaning up and cross-checking will be done before data processing and analysis.

\section{Data Processing, Analysis and Interpretation}

Data was checked for completeness and accuracy, sorted, categorized and summarized. Then collected data will be analyzed SPSS version 20. Descriptive Statistics and chi square test was done to describe study variables and identify associated factors. Associations between socio-demographic characteristics and job satisfaction, as well as comparison of overall level of job satisfaction with each factors of satisfaction were assessed for statistical significance using the chi square test. P-values less than or equal to 0.05 were considered statistically significant.

The level of job satisfaction was interpreted using a mean score for each factor. Accordingly, the mean score of four and above was taken as being satisfied for each factor while the mean score of below four was classified as being dissatisfied. The overall levels of job satisfaction among nurses work in operation room was classified as being dissatisfied if the sum of the scores for the different factors is between 20-60,while 61-80 is moderate and $81-120$ is satisfied.

\section{Ethical Consideration}

A letter of support and permission was obtained from the ethical review board of the Jimma University institutes of health science, school of nursing and midwifery. The advantage and purpose of the study was explained to the participants. For confidentiality Verbal consent was taken from the study participants.

\section{Operational About Level of Satisfaction}

Satisfied: If overall score for job satisfaction Score is81-120 [33]

Moderate satisfied: If overall score for job satisfaction Score is 61-80 [33]

Dissatisfied: If overall score for job satisfaction Score is below 60 [33]

\section{Results}

\section{Socio-Demographic-Characteristics}

A total of 98 nurses work in operation theater room have responded for the self-administered questionnaire. Out of 98 respondents who were included in this study, $42.85 \%$ are male and $57.1 \%$ are female. The majority of respondents are between the ages $31-40$ years (55.1\%), 29.6\% of them are below the age of 30 years. More than half $(58.2 \%)$ of the respondents were married. Regarding the work experience the greatest number of employees have service year between 1-5 years (69.4\%). With regard to educational qualification, $56.1 \%$ of the participants were in possession of diploma while $43.9 \%$ had BSC degree. (Table 1)

\begin{tabular}{|c|c|c|c|}
\hline \multicolumn{2}{|c|}{ Socio Demographic Variables } & \multirow{2}{*}{$\begin{array}{l}\text { No } \\
42 \\
\end{array}$} & \multirow{2}{*}{$\begin{array}{c}\text { Percent (\%) } \\
42.85 \\
\end{array}$} \\
\hline Cender & Male & & \\
\hline Genuer & Female & 56 & 57.14 \\
\hline \multirow{3}{*}{ Age in Years } & $\leq 30$ & 29 & 29.6 \\
\hline & $31-40$ & 54 & 55.1 \\
\hline & $\geq 41$ & 15 & 15.3 \\
\hline \multirow{2}{*}{ Marital status } & Single & 38 & 38.8 \\
\hline & Married & 57 & 58.2 \\
\hline \multirow{4}{*}{ Working experience in years } & $<1$ & 7 & 7.1 \\
\hline & 5-Jan & 68 & 69.4 \\
\hline & 10-Jun & 20 & 20.4 \\
\hline & $>10$ & 3 & 3.1 \\
\hline \multirow{2}{*}{ Educational qualification } & Diploma & 55 & 56.1 \\
\hline & BSC & 43 & 43.9 \\
\hline \multirow{2}{*}{ Part time Job } & Yes & 6 & 6.1 \\
\hline & No & 92 & 93.9 \\
\hline \multirow{5}{*}{ Working hours per week } & $\leq 50 \mathrm{hrs}$ & 19 & 19.4 \\
\hline & $51-60 \mathrm{hrs}$ & 35 & 35.7 \\
\hline & $61-70 \mathrm{hrs}$ & 28 & 28.6 \\
\hline & $71-80 \mathrm{hrs}$ & 13 & 13.3 \\
\hline & $>81 \mathrm{hrs}$ & 3 & 3.1 \\
\hline \multirow{3}{*}{ Type of hospital } & Teaching & 27 & 27.6 \\
\hline & General & 13 & 13.3 \\
\hline & District & 58 & 59.2 \\
\hline
\end{tabular}

Citation: Admasu BG, Abdela AD, Temamen TY, Dagmawit BK (2018) Job Satisfaction and Associated Factors among Nurses Page 2 of 7 Working In the Operation Theater at Government Hospitals of Eastern Ethiopia, 2017. Palliat Med Care 5(2): 1-7. DOI: http://dx.doi. 
Overall mean for job satisfaction among various factors. Overall mean for job satisfaction among various conditions revealed that the nurse work in operation room were satisfied with five factors, satisfaction in helping others 4.46(0.943), Status as a healthcare professional 4.06 (1.291), providing good quality of patient care 4.06(1.120), the recognition they get for good work 3.98 (1.065), and Patient outcome 3.95 (1.170) (table 2). According to the mean score of each the nurses work in operation room were dissatisfied with the remaining fifteen factors. The highest level of dissatisfaction was reported for Opportunity for training or education 1.36 (0.503). This was followed by house allowance1.53 (0.749), hazard allowance for nurse, 1.93 (0.259) the availability of resource and supplies 2.17 (0.800), feeling about job itself 2.85 (1.319) Salary (3.20 \pm 1.535$)$ respectively. (Table 2)

Table 2: Job satisfaction for each factor of nurses who working in operation room at government hospitals in East Arsi and East Shewa, June 1, 2017.

\begin{tabular}{|c|c|}
\hline Factors of Satisfaction & $\begin{array}{l}\text { Overall Mean } \\
\quad+\text { SD }\end{array}$ \\
\hline The availability of resource and supplies & $2.17 \pm 0.800$ \\
\hline Helping others & $4.46 \pm 0.943$ \\
\hline $\begin{array}{l}\text { Surgeons' attitudes towards Nurses working in } \\
\text { the operating theatre }\end{array}$ & $3.65 \pm 1.500$ \\
\hline Public awareness about the role of OR Nurse & $3.31 \pm 1.16$ \\
\hline Opportunities for advancement & $3.84 \pm 1.571$ \\
\hline Opportunity for training or education & $1.36 \pm 0.503$ \\
\hline Salary & $3.20 \pm 1.535$ \\
\hline Workload & $3.95 \pm 1.179$ \\
\hline Providing Quality patient care & $4.06 \pm 1.120$ \\
\hline Patient care outcome & $3.95 \pm 1.170$ \\
\hline $\begin{array}{l}\text { The amount of responsibilities given as a nurse } \\
\text { working in operating theatre }\end{array}$ & $3.94 \pm 1.208$ \\
\hline Physical working place conditions & $4.18 \pm 1.263$ \\
\hline The assistance you have in the operating room & $3.70 \pm 1.057$ \\
\hline $\begin{array}{c}\text { The freedom to choose your own method of } \\
\text { working }\end{array}$ & $3.77 \pm 1.110$ \\
\hline Your status as a healthcare professional & $4.06 \pm 1.291$ \\
\hline The recognition you get for good work & $3.98 \pm 1.065$ \\
\hline Remunerations & $3.24 \pm 1.104$ \\
\hline Hazard allowance for nurse in OR & $1.93 \pm .259$ \\
\hline Your feelings about job itself & $2.85 \pm 1.319$ \\
\hline
\end{tabular}

\section{Overall Level of Job Satisfaction and Associated Factors}

AAs it is shown on figure above the overall level of job satisfaction among nurses work in operation theater room from the total participant $8(8.16 \%)$ of the respondents were satisfied 39 (39.8\%) moderately satisfied while the remaining 51 (52\%) were dissatisfied (Figure 1).

\section{Overall Job Satisfaction Of Nurses Work In Operation Room}

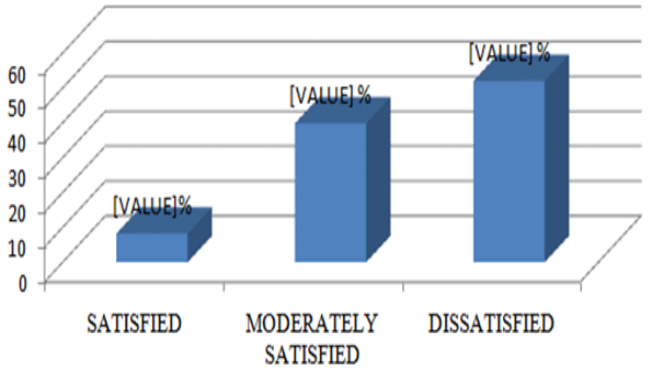

Figure 1: Overall level of job satisfaction of nurses working at government hospitals in East Arsi and East Shewa, June 1, 2017

Finding of the study showed that females are more dissatisfied 27 (52.9\%) than males highest dissatisfaction rate was in the age group between 31-40 24(47.1\%). Married respondents were more dissatisfied $30(58.8 \%)$ than single $21(41.2 \%)$. Most of the respondents at the educational level of Bsc were dissatisfied 32 (60.8\%). Respondents working in district hospital were more dissatisfied than those working at teaching hospital. Chi square test showed job satisfaction and type hospital were significantly associated with satisfaction of nurses working in the operating room $(\mathrm{p}=0.04)$. (Table 3 )

\section{Comparison of Factors Associated With Job Satisfaction}

Table 4; shows the chi-square analysis results of factors associated with job satisfaction. The results showed that satisfaction in helping others, providing good quality of patient care, Physical working, place conditions, Patient outcome, were significantly associated with job satisfaction. Almost (87.7\%) of respondents were highly satisfied with helping others, at $p$ value .000. Almost more than three-quarters $(76.5 \%)$ of participants were significantly satisfied with their providing good quality of patient care. The results also indicated that respondents were significantly satisfied with the freedom to choose method of working, public awareness about the role of operation room nurse and providing good quality of patient care at $\mathrm{p}$ value .001 . (Table 4)

\section{Discussion}

The finding of this study indicated that the overall level of job satisfaction among nurses work in operation theater; $8(8.16 \%)$ of the respondents were satisfied 39 (39.8\%) moderately satisfied while the remaining 51 (52\%) were dissatisfied. The finding revealed that house allowance, hazard allowance, the availability of resource and supplies, Opportunity for training or education, feeling about job itself and inadequate salary have a significantly influence the level of job satisfaction. In this study, majority of the respondents (52\%) were dissatisfied with their job. This findings were consistent with finding of study done in Pakistan, were 59\% of participants dissatisfied with their jobs [40]. 
Table 3: Association between socio demographic variables and overall job satisfaction of nurses working at government hospitals in East Arsi and East Shewa, Oromia regional state, June 1, 2017

\begin{tabular}{|c|c|c|c|c|c|}
\hline \multicolumn{2}{|c|}{ Characteristics } & \multicolumn{2}{|c|}{ Level of satisfaction } & \multirow{2}{*}{ P-value } & \multirow{2}{*}{ df } \\
\hline & & Satisfied & Dissatisfied & & \\
\hline \multirow{2}{*}{ Sex } & Male & 18 & 24 & \multirow{2}{*}{0.381} & \multirow{2}{*}{1} \\
\hline & Female & 29 & 27 & & \\
\hline \multirow{3}{*}{ Age } & $\leq 30$ & 9 & 20 & \multirow{3}{*}{0.093} & \multirow{3}{*}{2} \\
\hline & $31-40$ & 30 & 24 & & \\
\hline & $\geq 41$ & 8 & 7 & & \\
\hline \multirow{2}{*}{ Marital status } & Single & 19 & 21 & \multirow{2}{*}{0.94} & \multirow{2}{*}{1} \\
\hline & Married & 28 & 30 & & \\
\hline \multirow{4}{*}{ work experience (years ) } & $<1$ & 3 & 4 & \multirow{4}{*}{0.649} & \multirow{4}{*}{3} \\
\hline & 5-Jan & 31 & 37 & & \\
\hline & 10-Jun & 12 & 8 & & \\
\hline & $>10$ & 1 & 2 & & \\
\hline \multirow{2}{*}{ Educational qualification } & Diploma & 28 & 20 & \multirow{2}{*}{0.128} & \multirow{2}{*}{1} \\
\hline & Bsc & 19 & 31 & & \\
\hline \multirow{2}{*}{ Part time Job } & Yes & 2 & 4 & \multirow{2}{*}{0.459} & \multirow{2}{*}{1} \\
\hline & No & 45 & 47 & & \\
\hline \multirow{5}{*}{ working hours per week } & $\leq 50$ & 5 & 14 & \multirow{5}{*}{0.09} & \multirow{5}{*}{4} \\
\hline & $51-60$ & 20 & 15 & & \\
\hline & $61-70$ & 15 & 13 & & \\
\hline & $71-80$ & 7 & 6 & & \\
\hline & $>81$ & 0 & 3 & & \\
\hline \multirow{3}{*}{ Type of hospital } & Teaching & 14 & 13 & \multirow{3}{*}{$0.041^{*}$} & \multirow{3}{*}{2} \\
\hline & General & 2 & 11 & & \\
\hline & District & 31 & 27 & & \\
\hline
\end{tabular}

Table 4: Shows the chi-square analysis results of factors associated with job satisfaction among Nurses working at government hospitals in East Arsi and East Shewa, Oromia regional state, June 1, 2017

\begin{tabular}{|c|c|c|c|c|}
\hline \multirow{2}{*}{ Job characteristic } & \multicolumn{2}{|c|}{ Overall Level of satisfaction } & \multirow{2}{*}{$P$-value } & \multirow{2}{*}{ df } \\
\hline & Satisfied & Dissatisfied & & \\
\hline \multirow{2}{*}{ The availability of resource and supplies } & 4 & 43 & \multirow{2}{*}{0.614} & \multirow{2}{*}{2} \\
\hline & 3 & 48 & & \\
\hline \multirow{2}{*}{ Helping others } & 47 & 0 & \multirow{2}{*}{0} & \multirow{2}{*}{3} \\
\hline & 12 & 39 & & \\
\hline \multirow{2}{*}{ Surgeons' attitudes towards OR Nurse } & 37 & 10 & \multirow{2}{*}{0.013} & \multirow{2}{*}{4} \\
\hline & 28 & 23 & & \\
\hline \multirow{2}{*}{ Public awareness about the role of OR Nurse } & 33 & 14 & \multirow{2}{*}{0} & \multirow{2}{*}{5} \\
\hline & 15 & 36 & & \\
\hline \multirow{2}{*}{ Opportunities for advancement } & 30 & 17 & \multirow{2}{*}{0.14} & \multirow{2}{*}{5} \\
\hline & 25 & 26 & & \\
\hline
\end{tabular}




\begin{tabular}{|c|c|c|c|c|}
\hline \multirow{2}{*}{ Opportunity for training or education } & 3 & 44 & \multirow{2}{*}{0.357} & \multirow{2}{*}{5} \\
\hline & 6 & 45 & & \\
\hline \multirow{2}{*}{ Salary } & 27 & 20 & \multirow{2}{*}{0.017} & \multirow{2}{*}{4} \\
\hline & 17 & 34 & & \\
\hline \multirow{2}{*}{ Total working hours } & 36 & 11 & \multirow{2}{*}{0.061} & \multirow{2}{*}{5} \\
\hline & 30 & 21 & & \\
\hline \multirow{2}{*}{ Providing good quality of patient care } & 43 & 4 & \multirow{2}{*}{0.001} & \multirow{2}{*}{5} \\
\hline & 32 & 19 & & \\
\hline \multirow{2}{*}{ Patient outcome } & 40 & 7 & \multirow{2}{*}{0.004} & \multirow{2}{*}{5} \\
\hline & 30 & 21 & & \\
\hline \multirow{2}{*}{ The amount of responsibilities you are given } & 41 & 6 & \multirow{2}{*}{0} & \multirow{2}{*}{5} \\
\hline & 28 & 23 & & \\
\hline \multirow{2}{*}{ Physical working place conditions } & 38 & 9 & \multirow{2}{*}{0.003} & \multirow{2}{*}{5} \\
\hline & 27 & 24 & & \\
\hline \multirow{2}{*}{ The assistance you have in operating room } & 36 & 11 & \multirow{2}{*}{0.024} & \multirow{2}{*}{4} \\
\hline & 28 & 23 & & \\
\hline \multirow{2}{*}{$\begin{array}{l}\text { The freedom to choose your own method of } \\
\text { working }\end{array}$} & 39 & 8 & \multirow{2}{*}{0} & \multirow{2}{*}{5} \\
\hline & 25 & 26 & & \\
\hline \multirow{2}{*}{ Your status as a healthcare professional } & 37 & 10 & \multirow{2}{*}{0.034} & \multirow{2}{*}{5} \\
\hline & 30 & 21 & & \\
\hline \multirow{2}{*}{ The recognition you get for good work } & 41 & 6 & \multirow{2}{*}{0.01} & 5 \\
\hline & 33 & 18 & & \\
\hline Remunerations for nersonal nrotective equinment & 24 & 23 & 0.075 & 5 \\
\hline (2) & 17 & 34 & & \\
\hline Hazard ollowance for nurce in $0 \mathrm{P}$ & 6 & 41 & 0041 & 4 \\
\hline 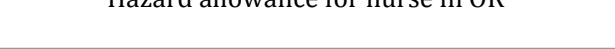 & 1 & 49 & 0.041 & ${ }^{4}$ \\
\hline House allowance & 2 & 45 & 0.51 & 3 \\
\hline 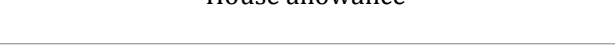 & 1 & 50 & 0.01 & S \\
\hline Your feelings about job itself & 17 & 30 & 0.171 & 5 \\
\hline
\end{tabular}

The study finding is also consistent with study conducted among operation room nurses in Nigeria in which $59 \%$ of the operation room nurses were dissatisfied with their job while $8.7 \%$ were very satisfied, $6.5 \%$ were very dissatisfied with their job [30]. Reason for dissatisfaction was reported as low salary $(60.3 \%)$, little opportunity for further education, inadequate facility and supplies (20.1\%) [18-20]. Dissatisfaction with regard to salaries and benefits in this study finding seems to be a common issue that evident in several studies [42].

The commonest reasons given for job satisfaction according to this study were the helping others $(87.8 \%)$ providing good quality of patient care $(76.5 \%)$, the recognition you get for good work (75.5\%), Patient outcome (71.4\%), the amount of responsibilities you are given $(70.4 \%)$. That agrees with the findings of Singh et al. who reported that anesthetists appreciated the good quality of patient care and intellectual stimulation as well as enjoyed the interaction with anesthesia colleagues and magic of anesthesia. [43]
A study at Jimma university specialized hospital showed that $(46.2 \%)$ of the health workers are dissatisfied with their job. The major reasons reported for their dissatisfaction were lack of motivation, inadequate salary, insufficient training opportunities and inadequate number of human resources. The rest $57.8 \%$ respondents were satisfied with their job, the major reasons given were getting satisfaction from helping others and professional gratification. Suggestion given by the respondents to improve job satisfaction and increase retention rate included motivation of staff through different incentives such us bonus, house allowance, salary increment, establishing good administration management system and improving hospital facilities and infrastructure.[41]

In Ethiopia the related categories of study were not conducted in operation theater department and other department job satisfaction or dissatisfaction of nurse but generally, Ethiopia health service organization and management was studied from1995-2000 E.c for all health profession job satisfaction and dissatisfaction including nursesthe finding indicated satisfaction 
from helping others and profession gratification and the majority of respondents dissatisfied due to low salary, inadequate opportunity for further education, inadequate facility and supplies $[18,19]$ respectively.

\section{Conclusion}

In conclusion the finding of this study indicated that there is a low level of job satisfaction among of nurses working at government hospitals in East Arsi and East Shewa, Oromia regional state. The major reasons of dissatisfaction were lack of houses allowance, house, inadequate salary, and inadequate opportunity for training or education, insufficient resources and supplies and feeling about job. The findings this study concluded that the main factors that are associated with overall job satisfaction were satisfaction in helping others, providing good quality of patient care, responsibilities, recognition for good work and patient care outcome.

\section{Conflict of Interests}

All authors declared that they have no conflict of interests. Jimma University covered only the survey cost for this study and there is no any funding organization.

\section{Authors' Contribution}

Abdela Abdu and Admasu Belay conceived and designed the protocol. Additionally Abdela Abdu performed the data collection. Admasu Belay, Temamen Tesfaye and Dagmawit Birhanu contributed on data analysis, and checked the draft. Dagmawit Birhanu and Temamen Tesfaye prepared manuscript. Admasu Belay approved it. All authors read and approved the final paper.

\section{Acknowledgements}

We would like to thank the east Arsi zone public hospitals operation room staffs nurses as well as the administrative staffs for all the help and support given for us during the data collection period. We also thank Jimma university institute of health for permitting us to conduct this study.

\section{References}

1. Mahmood A, Nudrat S, asdaque MM, Nawaz A, Haider N. Job Satisfaction of Secondary School Teachers: a comparative analysis of gender, urban and rural Schools. Asian Social Science. 2011; 7(8):203-207. DOI:10.5539/ass.v7n8p203

2. From the department of emergence medicine metro health medical center and the department of Epidemiology and biostatic, case western Reserve university, cleaved, $\mathrm{OH}$ (cydulka); and the American board of Emergence medicine , East Lansing, MI

3. Corpondences to: Judith K. Sluiter, coronel institute for occupation and environment health /Academic medical center, university of Amsterdam meibergreef 9,1105, The Netherland

4. Pillay R. work satisfaction of professional nurses in South Africa: a comparative analysis of the public and private sectors. BMC Human Resources for Health. 2009; 7(15).DOI: 10.1186/1478-4491-7-15

5. Freeborn DK, Hooker RS. Satisfaction of physician assistants and other non-physician providers in a managed care setting. Public Health Report. 1995;110(6): 714-719.
6. Eker l, Tuzun Eh, Dasakapan A, Surenkok 0. Predictors of job satisfaction among physiotherapists in Turkey. J Occup Health. 2004;46(6):500-505.

7. Appleton K, House A, Dowell A. a survey of job satisfaction, sources of stress and psychological symptoms among general practitioners in Leeds. Br J Gen Pract. 1998;48 (428): 1059-1063.

8. Mahmoud al-hussami, RN. A Study of Nurses' Job Satisfaction: The relationship to organizational commitment, Perceived organizational Support, Transactional leadership Transformational leadership, and level of education. European Journal of Scientific Research. 2008; 22(2): 286-295.

9. Haas JS, cook EF, Helen R, Puopolo SA, BurstinnHR, Cleary PD, et al. Is the professional satisfaction of general interests associated with patient satisfaction? J Gen Intern Med. 2000; 15(2): 122-128. DOI: $10.1046 / \mathrm{j} \cdot 1525-1497.2000 .02219 . x$

10. Buciunienei, Blazeviciene A, Bliudziute E. Health care reform and job satisfaction of primary health care physicians in lithuania.BMC Family Practice. 2005; 6: 10. DOI: 10.1186/1471-2296-6-10

11.Grembowski D, Ulrichc M, Paschane D, Diehr P, Katon W, Diane M, et al. Managed care and Primary Physician Satisfaction. JABFP. 2003;16(5): 383-393. DOI: 10.3122/jabfm.16.5.383

12. Hoogendoorn WE, Bongers PM, de Vet HC, Ariëns GA, van Mechelen W, Bouter LM. High physical work load and low job satisfaction increase the risk of sickness absence due to low back pain: results of a prospective cohort study. Occup Environ Med. 2002; 59(5):323328.

13. Fahrenkopf AM, Sectish TC, Barger LK, Sharek PJ, Lewin D, Chiang VW, etal. Rates of medication errors among depressed and burn tout residents: prospective cohort study. BMJ. 2008; 336(7642):488491. DOI: $10.1136 /$ bmj.39469.763218.

14. Freeborn DK. Satisfaction, commitment, and psychological wellbeing among HMO physicians. West J Med. 2001; 174(1):13-18.

15. Augusto Land JM, Lopez-zafar E, BerriosMartos MP, Aguilar-Luzon Mdel C. The relation between emotional intelegence, occupatiol stress and health in nurse: a questionnaire survey. Int J Nurs stud. 2008; 45(6):888-901. DOI: 10.1016/j.ijnurstu.2007.03.00

16.Poncet MC, Toullic P, Papazian L, Kentish-Barnes N, Timsit JF, Pochard F, et al. Brunoutsydrome in critical care nursing staff. Am J Respir Crit Care Med. 2007; 175(7):698-704. DoI: 10.1164/ rccm.200606-8060C

17. Curationi Journal of the democratic nursing organization of South Africa.

18.Yami A, Hamza L, Hassen A, Jira C, Sudhakar M. Job satisfaction and its determinants among health workers in jimma university specialized hospital, southwest Ethiopia. Ethiop J Health Sci. 2011; 21(Suppl 1): 19-27.

19. Government of Ethiopia and the World Bank, author. Health Sector Review, Ethiopian social sector studies. 1st Ed. Addis Ababa: Mega; 2004

20.European commission. Employment Europe. 2002.

21. Lin BY, WanTT, Hsu CP, Hung FR, Juan CW, Lin CC. Institute of Health Services Administration, College of Public health , China Medical University, Taichung, Taiwan, ROC. Health Serve manage Res. (2012); 25(2):68-77. doi:10.1258/hsmr.2012.01011 
22. Mohammad Abul Bashar Sarker, Md. Harun-Or-Rashid, Joshua A Reyer, Tomoya Hirosawa,Yoshitoku Yoshida, Mohammod Monirul Islam, et al. Associations of socioeconomic determinants with community clinic awareness and visitation among women: evidence from Bangladesh Demographic and Health Survey-2011. BMC Res Notes. 2015; 8: 590. DOI: 10.1186/s13104-015-1374-7

23.Armstrong M. A Handbook of Human resource management practice. Tenth Edition. 2006; Kogan Page publishing: London.

24.George, J.M and Jones, G.R. Understanding and managing organizational behaviors. Fifth Edition. 2008; Pearson /prentice Hall: New Jersey.

25.AONE. Guiding principle for excellence in Nurse/physician Relationships. 2002

26. Rosenstein AH, O'Daniel M. Disruptive Behavior and clinical outcomes: perception of nurse and physician. Am J Nursing; 2005; 105(1): 54-64.

27. CemilKuzey. European journal of economic and political studies. ROAD. 2007.

28. Hollyford S, Whiddett S. The motivation handbook. 2002; London: CIPD.

29. Robert Kreitner, Angelo Kinicki, Buelens. Organizational behavior second Edition. 1992: Trove: Australia

30. RukeweA, FatiregunA,Oladunjoye AO, Oladunjoye. Job Satisfaction among Anesthesiologists at Tertiary Hospitals in Nijgeria. Saudi Anaesth.2012; 6(4):341-343. DOI: 10.4103/1658-354X.105857:

31. Lee Cheng Poh. Nurses job satisfaction in the Malaysia private hospitals. 2008.

32. Michael A. Shields, Melanie E, WARD, PSERC. Nurses, Job satisfaction, Quitting intention, principal component Analysis. Journal of Health Economics. 2001; volume20 issue 5: pages-677-701. DOI: 10.1016/ S0167-6296(01)00092-3

33. Okaroao, eze cu, ohagwu. Survey of Job Satisfaction among Nigerian radiographers in Southeastern Nigeria. European Journal of Scientific Research, Global Journal of Medical Research. 2015; Volume 15 Issue 2: page no.448-456
34.OXFORD Advanced learner's Dictionary of current English / new student edition As How by fifteen editions, Editor Jonathan Crawther, Assistant Editor Kathryn Cavanaugh, phonetics Editor Michael Ash by, Oxford University press(book).

35. Collins English Dictionary-complete and Unabridged 10thEdition (2009) williamcollinssonsandco.ltdHarpercollins publishers cite this source

36.Gifford BD, Zammuto RF, Goodman EA. The relation between hospital unit culture and nurses quality of work life. J Healthc Manag. 2002; volume 47 issue (1): page no. 13-25

37. Aiken LH, Sloane DM, Lake ET. Satisfaction with patient acquired immunodeficiency syndrome care: A national comparison of dedicates and scattered-bed units. Med Care. 1997; volume 35 issue (9): 948-62.

38.Geletoetal.BMC Res Notes (2015) 8:394

39. Sindu, H ,(2015) Geletoetal.BMC Res Notes (2015) 8:394

40.Ramesh Kumar, Jamil Ahmed, Babar Tasneem Shaikh, Rehan Hafeez, Assad Hafeez Job satisfaction among public health professional working in public sectors: cross sectional study from Pakistan . Hum Resour Health. 2013; volume11 issue 2: doi: 10.1186/14784491-11-2

41. Alemshet Yami, Leja Hamza, Alima Hassen, Challi Jira, Morankar Sudhakar. Job satisfaction and its determinants among health workers in Jimma university specialized hospital, Ethiop J Health Sci. 2011; 21 (Suppl 1): 19-27

42. Mulugetamekuria, AyelowGeleto Factors associated with job satisfaction among health works at public hospitals of west shoa zone, Oromia regional state, Ethiopia. Science Journal of Public Health. 2015; 3 (2):

43.Sanjeev Singh, Arti Singh, Anbarasu Annamalai ,Gaurav Goel. Anaesthesiology as a Career Vis-À-Vis Professional Satisfaction in Developing Countries. J Anesthe. 2013; 4:304: doi: 10.4172/21556148 